Portland State University

PDXScholar

$1-1-2003$

\title{
Comparative studies of evolutionary responses to light environments in Arabidopsis
}

\author{
Massimo Pigliucci \\ University of Tennessee - Knoxville \\ Heidi Pollard \\ University of Tennessee - Knoxville \\ Mitchell B. Cruzan \\ Portland State University
}

Follow this and additional works at: https://pdxscholar.library.pdx.edu/bio_fac

Part of the Biology Commons, and the Plant Breeding and Genetics Commons

Let us know how access to this document benefits you.

\section{Citation Details}

Pigliucci, M., Pollard, H., and Cruzan, M. B. (2003). Comparative Studies of Evolutionary Responses to Light Environments in Arabidopsis. American Naturalist, 161(1), 68.

This Article is brought to you for free and open access. It has been accepted for inclusion in Biology Faculty Publications and Presentations by an authorized administrator of PDXScholar. Please contact us if we can make this document more accessible: pdxscholar@pdx.edu. 


\title{
Comparative Studies of Evolutionary Responses to Light Environments in Arabidopsis
}

\author{
Massimo Pigliucci, ${ }^{1,2,{ }^{*}}$ Heidi Pollard, ${ }^{1}$ and Mitchell B. Cruzan ${ }^{2}$
}

1. Department of Botany, University of Tennessee, Knoxville, Tennessee 37996-1100;

2. Department of Ecology and Evolutionary Biology, University of Tennessee, Knoxville, Tennessee 37996-1100

Submitted October 24, 2001; Accepted April 11, 2002;

Electronically published December 30, 2002

ABSTRACT: In this article, we compare the reaction norms to foliage shade (changes in light quality, spatially fine-grained environmental variation) and photoperiod (day length, spatially coarse-grained environmental variation) in several haplotypes of Arabidopsis thaliana from Scandinavia. We found that both across-environment means and phenotypic plasticities evolved continuously and very rapidly within this group. Both character means and trait plasticities were highly integrated, in part as predicted by the adaptive plasticity hypothesis for response to foliage shade (the so-called shade-avoidance syndrome). We found that a significant but small fraction of the variance in across-treatment trait means and plasticities in response to one environmental factor is explained by variation of the same traits in response to the other factor. Genetic relatedness based on chloroplast DNA sequence variation among haplotypes was not associated with variation in across-treatment character means or their plasticities, suggesting that evolution of these characters has occurred on a local geographic scale via reticulation (outcrossing) among maternal lines rather than by the differential survival of selfing lineages.

Keywords: Arabidopsis, shade avoidance, comparative method, haplotypes, phenotypic plasticity, network phylogenies.

Two major strategies allowing organisms to contend with local environmental conditions are phenotypic plasticity and genetic adaptation (van Tienderen 1991, 1997). These in turn are inextricably related to the grain of the particular aspect of the environment as perceived by the organism (Levins 1963; Gillespie 1974). When the environment varies at a small scale, plasticity may be advantageous if the genotype's response to such environmental heterogeneity

\footnotetext{
* Corresponding author; e-mail pigliucci@utk.edu.
}

Am. Nat. 2003. Vol. 161, pp. 68-82. (C) 2003 by The University of Chicago. 0003-0147/2003/16101-010379\$15.00. All rights reserved. keeps its relative fitness more or less constant (van Tienderen 1991; Gabriel and Lynch 1992; Winn 1996; DeWitt et al. 1998). However, if the environment varies at a scale that is larger than the typical dispersal distance of a species, the likely outcome is genetic adaptation to local conditions (Bell 1997; Pigliucci 2001). Of course, natural environments are composed of numerous interacting factors; some of these are invariant at spatial and temporal scales relevant to the organism, and others change at those same scales.

Light is one such environmental factor that is characterized by components that vary at different scales. It is a complex cue that influences several aspects of the life cycles of plants and animals (e.g., Leimar 1996; Densmore 1997; Junttila et al. 1997; Hau et al. 1998). In plants, while the quantity of available light affects the efficiency of photosynthesis (Frankland 1986), light spectral quality (measured as the ratio between the red and far-red components of the spectrum, R : FR) marks the presence of competing neighbors (which absorb the photosynthetically active radiation while reflecting the rest; Schmitt and Wulff 1993). Moreover, the length of time that light is available each day indicates seasonal changes and affects the timing of crucial life-history events such as dormancy and reproduction.

In this article, we use a comparative approach to examine the response of Arabidopsis thaliana (Brassicaceae) to light quality (a spatially fine-grained variable) and contrast it to its response to day length (a spatially coarsegrained variable, though it varies temporally and predictably throughout the life cycle of the organism) as investigated in our previous article (Pollard et al. 2001). We used Arabidopsis because it is a model system for both molecular-developmental biology (Pyke 1994) and ecological genetics (Pigliucci 1998). Since this system is so well studied, there are already considerable data on the molecular basis of its responses to light (e.g., Janoudi et al. 1997; Whitelam and Devlin 1998), although much less is known about its population biology and evolution (e.g., Clauss and Aarssen 1994; Thompson 1994; Zhang and Lechowicz 1994; Pigliucci and Schlichting 1998).

We investigated phenotypic responses to light quality 
and day length in the context of phylogenetic relationships to test whether these characters and the association between them are evolutionarily labile. For example, Arabidopsis genotypes present in northern latitudes could all be descended from common ancestors that persisted through colder periods of the Pleistocene at higher elevations of southern regions. Alternatively, lineages may have become adapted to local conditions as they dispersed north from southern latitudes. In the former case, northern genotypes should be more closely related to each other than to southern lineages, while in the latter case, we would expect phylogenetic relationships to have minimal explanatory power to account for variation in light responses. Expectations for the evolution of phenotypic plasticity are similar: genotypes in heterogeneous environments may be descended from common ancestors, or plasticity may have evolved only recently in response to levels of local environmental variation. Beginning to distinguish between these alternative scenarios will clarify whether the acrosstreatment means and plasticities of these characters can respond rapidly to environmental changes or whether phylogenetic inertia for these traits leads to consistent habitat affinities for closely related lineages.

In Arabidopsis, aspects of light availability are perceived by two known groups of photoreceptors, phytochromes (PHY) and cryptochromes (CRY) (Kendrick et al. 1994). The roles of these photoreceptors are only partially distinct (Somers et al. 1998; Ballaré 1999), opening the possibility that the evolution of responses to day length and foliar shade may not be independent of each other. Indeed, other studies suggest that pleiotropic effects of these genes may manifest themselves in the form of genetic correlations, potentially affecting the evolutionary trajectories of Arabidopsis populations. Mozley and Thomas (1995), for example, carried out experiments providing evidence that PHYA, PHYB, and CRY1 are all responsive to day length. Further work by Guo et al. (1998) indicates that CRY2 is also involved, particularly in the control of flowering time.

Changes in the $\mathrm{R}$ : FR ratio trigger the so-called shadeavoidance syndrome, which includes early flowering, reduced branching, and increased vertical growth as means to maximize interception of sunlight and to reduce the impact of forthcoming competition (Schmitt 1997; Gilbert et al. 2001). The shade-avoidance syndrome is largely triggered by PHYB (Smith and Whitelam 1997), although Aukerman et al. (1997) and Devlin et al. (1999) found evidence that PHYD is also important in this plasticity syndrome, and work by Devlin et al. (1998) implicates PHYE as well. The multiple functions that have been described for each of these loci suggest that shade avoidance and response to day length may constrain each other's evolution for two reasons: first, these two components of light availability are perceived in part by the same pho- toreceptors; and second, even though the light signals follow partially independent transduction pathways, they have to converge on the occasion of crucial life-history decisions, such as the time of transition from the vegetative to the reproductive phase (Kuittinen et al. 1997). Accordingly, the signals derived from gauging day length and light quality must eventually be integrated into one developmental switch.

At the ecological level, however, these aspects of light quality and availability are not coupled. Day length changes with latitude; thus, one would expect evolution of a specialist in response to an environmental factor that is heterogeneous at a coarse spatial scale. In contrast, light quality, as altered by foliage shade, varies at a much smaller spatial (and temporal) scale, sometimes within a meter or less (Callahan and Pigliucci 2002). One would then expect evolution of plasticity for shade avoidance whenever the $\mathrm{R}$ : FR ratio varies substantially from place to place during a season (not, e.g., in the case of plants permanently living in the understory; Bradshaw and Hardwick 1989). With respect to these two aspects of light, an evolutionary dilemma may therefore arise. Since a plant has but a limited number of chances to make critical life-history decisions such as flowering, if the optimal response to day length is different from the optimal shade-avoidance response, independent adaptation to the two environmental factors should be the target of selection. If that is not possible because of the genetic architecture of the two phenotypes, some kind of ecologically viable compromise must be reached.

In this study, we focused on plants collected in Scandinavia, part of the northernmost limit of the natural range for this genus. Scandinavian genotypes are exposed to steep variation in day length over a relatively short latitudinal range. In the same area, $A$. thaliana and some of its close relatives also experience a variety of local conditions, growing from bare soil with sparse or nonexistent vegetation to relatively thick canopies of grass and other low cover (M. Pigliucci, personal observation). In this sense, therefore, Scandinavia presents a convenient contrast of a variety of environmental conditions both at the very small scale of individual plants within populations (light quality) and at the larger scale of geographic variation across populations (day length).

Here we investigate the evolution of shade-avoidance responses in the same haplotypes considered in Pollard et al. (2001) and discuss differences in the patterns of evolution of across-treatment character means and plasticities in response to photoperiod and foliar shade. We address the following questions: (1) Is there differentiation among Scandinavian haplotypes for across-treatment trait means and plasticities when plants are exposed to contrasting regimes of light spectral quality? Such differences would 
indicate the past action of evolutionary processes that have modified the reaction norms under study. (2) Do the across-treatment trait means or plasticities coevolve (i.e., are they phenotypically integrated)? This would be expected in order to maintain an adaptive phenotypic "syndrome" such as shade avoidance. (3) Are the patterns of coevolution of across-treatment trait means or plasticities to foliar shade different from those characterizing the response to photoperiod (Pollard et al. 2001)? This would suggest the operation of different evolutionary mechanisms affecting phenotypic responses to distinct aspects of the light environment. (4) Do the across-treatment mean and plasticity to foliar shade of the same trait coevolve, or do they behave as independent characters as originally suggested by Bradshaw (1965)? There is no a priori reason to consider these two aspects of reaction norms as biologically interdependent, so this is an open question in any study of reaction norm evolution. (5) Is the geographical distance among accessions a good predictor of phenotypic differentiation in either across-treatment trait means or plasticities? If so, one might suspect a combination of long-distance dispersal and genetic drift to be important in shaping the degree of interaccession differentiation, since there are no obvious ecological correlates to simple geographical distance in these accessions. (6) Are across-treatment trait means and plasticities evolutionarily labile, or are similar phenotypes more closely related to each other than they are to genotypes with contrasting responses? The first outcome would suggest rapid evolution and little if any genetic constraints on reaction norms, while phylogenetic conservativeness would favor the constraint hypothesis (unless genetically close accessions also happen to colonize similar habitats).

\section{Material and Methods}

\section{Plant Material}

Eight Scandinavian accessions of Arabidopsis thaliana (L.) Heynh. (Brassicaceae) were used, with seeds provided by the Arabidopsis Information Resource, which can be found at http://www.arabidopsis.org. Two accessions were from Denmark (CS1220 and CS1288), two from Finland (CS1144 and CS1160), two from Norway (CS1436 and CS1643), and two from Sweden (CS1352 and CS1430). Since these had been maintained by single-seed descent, it was possible to study only one haplotype per accession. While this is a limitation for our study, current estimates of population structure in Arabidopsis indicate that in fact each natural population contains one or very few genotypes and that most of the genetic variation in this species is partitioned across populations (Abbott and Gomes 1989).
Known latitudes for the chosen accessions (excluding Finland 1160, for which the exact collection site is unknown) vary from $50^{\circ} \mathrm{N}$ to $61^{\circ} \mathrm{N}$; longitudes vary from $6^{\circ} \mathrm{E}$ to $25^{\circ} \mathrm{E}$; altitudes range from $1 \mathrm{~m}$ to $200 \mathrm{~m}$. At these localities, average daily temperatures vary from $4^{\circ} \mathrm{C}$ to $8^{\circ} \mathrm{C}$ in April and from $16^{\circ} \mathrm{C}$ to $18^{\circ} \mathrm{C}$ in July (Schonwiese and Rapp 1997), and summer photoperiod varies between 16 h $22 \mathrm{~min}$ and $19 \mathrm{~h} 17 \mathrm{~min}$.

Little is known of the local conditions (e.g., degree of competition from neighbors) of the populations from which our accessions were sampled, a situation that we are trying to remedy by conducting field studies on this species. However, Arabidopsis is an opportunistic ruderal species, so it is likely that it undergoes frequent local extinction and that the fine-grained characteristics at each location vary significantly from year to year. Only a longterm study of population dynamics would be able to shed some light on this aspect of the plant's ecology.

\section{Handling of Plants}

Seeds from all accessions were placed in the dark on moist substrate at $4^{\circ} \mathrm{C}$ for both experiments. Following vernalization, the seeds were germinated under the assigned light treatment: high or low light quality, as measured by the $\mathrm{R}$ : FR ratio. The trays were bottom watered as needed and fertilized weekly. Plants were grown in two growth chambers at the University of Tennessee, Knoxville. Both chambers were set at $22 \mathrm{~h}$ of light per day in order to be able to compare the results with one of the two day-length treatments used in the previous experiment (this comparison was done using matrix correlation tests and was therefore affected by the fact that the two experiments were conducted at different times; while the conditions were identical as far as we could tell, the outcome of such an analysis should nonetheless be considered only as indicative). Unfortunately, this means that plants were experiencing a longer photoperiod than natural, which may have affected our results; if so, the bias was the same one encountered in the previous experiment. The light quality was set at either $1: 1$ (high, equivalent to full sun conditions) $\mathrm{R}: \mathrm{FR}$ or $1: 2$ (low, indicative of foliar shade) $\mathrm{R}$ : FR. The treatments were created using Philips $20-\mathrm{W}$ lightbulbs for the high R:FR treatment and Philips 20W lightbulbs combined with Toshiba far-red bulbs for the low $\mathrm{R}$ : FR treatment. The temperature was maintained around $18^{\circ} \mathrm{C}$ for both experiments.

Various morphological traits were measured to quantify phenotypic variation among plants: number of rosette leaves at bolting (meristem allocation to vegetative growth); rosette diameter (extent of vegetative growth); days to bolting (time at which plants switch from the vegetative to the reproductive phase); length of the main 
stem (a measure of overall size during the reproductive phase); number of basal stems (an indication of plant architecture and potential for late reproduction); time of first seed set (interval between bolting and the ripening of the first seeds); number of fruits on the main stem (a partial measure of reproductive fitness); and number of fruits on the basal stem or stems (partial measure of reproductive fitness). The last two traits were measured at the end of the flowering period.

Replicates of each haplotype were obtained by selfing and exposed to each of the two light-quality treatments. There were 16 trays distributed across the two chambers (eight in each chamber, with four on the top shelf and four on the bottom shelf), with two randomly placed seedlings per accession per tray. Both treatments were applied in each chamber: in one chamber, the upper shelf hosted the high R : FR treatment, and the lower shelf hosted the low R : FR treatment; in the other chamber, the situation was reversed. While this obviously does not guarantee uniformity of the microenvironments, there was no confounding effect of chamber and treatment (although we did include a shelf effect in the analysis of variance; see "Statistical Analyses").

\section{Estimating Phylogenetic Distances}

Genetic distances among Arabidopsis haplotypes were inferred from chloroplast DNA (cpDNA) sequence variation (for details of methods used to obtain the sequence data, see Pollard et al. 2001). We examined genetic variation among accessions by sequencing three intergenic cpDNA regions that have previously been shown to display high levels of variation within and among species (trnT[UGU]-trnF[GAA]; Taberlet et al. 1991; Pollard et al. 2001). Data were analyzed using PAUP (version 4.0b1) on a Windows 2000 operating system. The three intergenic regions were combined and submitted to the program as a single sequence that was 2,100 bases long and contained 38 insertions/deletions (in/del), which were scored separately as individual characters regardless of their length (Swofford et al. 1996).

We estimated genetic distances among accessions using two different methods. The first method estimated substitution rates using the general time reversible (GTR) model (Swofford et al. 1996), with among-site variation following a gamma distribution (with the shape parameter equal to 0.5 and the proportion of invariable sites equal to 0; Swofford et al. 1996). The GTR model was chosen over less specific evolutionary models on the basis of recommendations made by Kumar et al. (1993). Since we were analyzing a relatively long sequence, the expected increase in the variance of our estimates from using a more complicated evolutionary model should not be too great
(Hillis et al. 1996). Furthermore, distance matrices obtained from a range of models (e.g., Jukes-Cantor, Kimura's two-parameter model, and Felsenstein's correcteddistance model; Jukes and Cantor 1969; Kimura 1980; Felsenstein 1984) were highly correlated (all matrix correlations were close to 1.0 ), so the choice of evolutionary models did not affect our results. For the second method, we used the mean number of pairwise differences between sequences (Swofford et al. 1996). This distance measure differs from the previous one since it allows the inclusion of insertion/deletion mutations, which were relatively common in the genomic region examined (Pollard et al. 2001).

Relationships among accessions based on the two distance methods described above were visualized using axial network phylogenies with reticulations placed on an additive tree so as to maximize the fit between the reticulogram and the data matrix (Lapointe 2000; Makarenkov and Legendre 2000; Makarenkov 2001). We used two different methods to determine the stopping point for the addition of reticulations $\left(\mathrm{Q}_{1}\right.$ and $\mathrm{Q}_{2}$; Makarenkov 2001). Each of these statistics seeks to maximize the fit between the reticulogram and the distance matrix while accounting for the number of degrees of freedom, but the $Q_{2}$ criterion usually is less stringent and allows for the addition of more connections than does $\mathrm{Q}_{1}$ (Makarenkov and Legendre 2000; V. Makarenkov and P. Legendre, unpublished manuscript). The patterns of connections among accessions obtained using the reticulogram procedures were similar to results from alternative methods for the analysis of distance matrices (e.g., pyramids and splitsgraphs; Bandelt and Dress 1992; Lapointe 2000).

While we are aware of skepticism of the possibility of conducting intraspecific phylogenetic studies in Arabidopsis (Sharbel et al. 2000), our results and those of others (Vander-Zwan et al. 2000) show that a phylogenetic signal is in fact detectable and can be used for comparative studies of phenotypic evolution in this species.

\section{Statistical Analyses}

We calculated the mean for each trait in each of the two light environments. The across-treatment mean-that is, the average between the two treatments-was also calculated for each trait. This value is important because it constitutes the other major attribute (other than plasticity) of a reaction norm, a quantity often referred to as the "height" (in an environment-phenotype graph) of the reaction norm in response to a particular environmental factor (Pigliucci 2001); this quantity is indicative of the average response exhibited by a genotype, and it is relevant because there is no a priori biological relationship between it and plasticity (although there is a mathematical expec- 

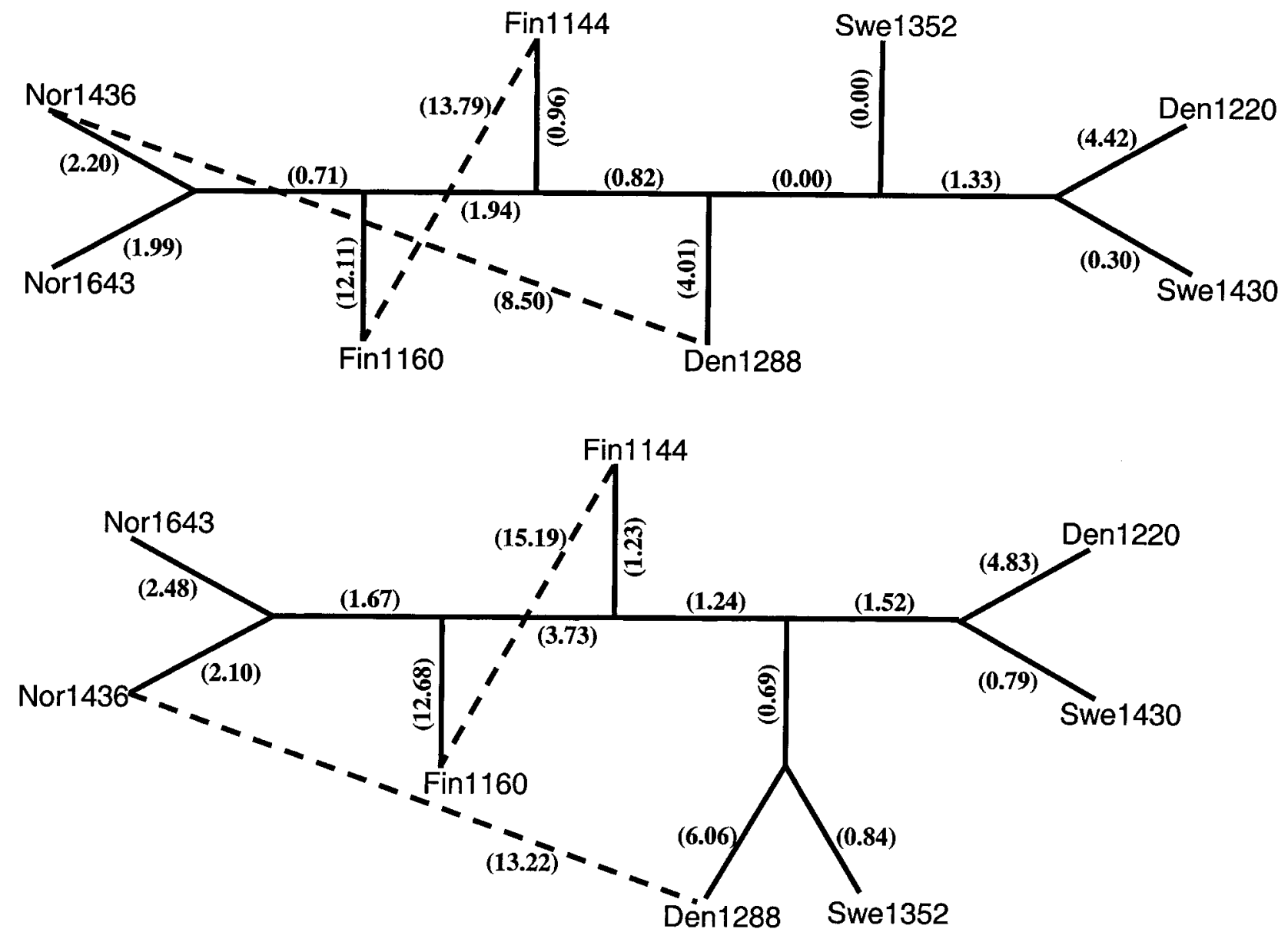

Figure 1: Networks indicating genetic relationships among populations. The upper diagram was obtained using the general time reversible matrix and the lower one with the mean distance matrix. Broken lines indicate possible reticulation events. Numbers are mutations separating each lineage.

tation of dependency between the two, especially in a twoenvironment setting). In these experiments, the plasticities were computed as the difference between the mean for the trait under high $\mathrm{R}$ : FR minus the mean for that trait under low R:FR (the sign was retained, since there was some crossing of the reaction norms).

Univariate multifactorial ANOVA provided a means to examine the effects of haplotype (genetic differentiation), treatment (overall plasticity), chamber (microenvironmental effects), shelf (nested within chamber; also a microenvironmental effect), and haplotype by treatment interaction (genetic differentiation for plasticity). All effects were considered fixed and therefore were tested over the mean square error term. All tests were performed first by using a nominal alpha value of 0.05 and then adjusted for multiple tests using a sequential Bonferroni correction. Data were transformed as appropriate in order to meet ANOVA assumptions (Sokal and Rohlf 1995).
Data were plotted as reaction norm diagrams with the treatment on the abscissa and the phenotypic value on the ordinate for each haplotype. In the diagrams (figs. 2, 3), ellipses encompass within-treatment means that were not significantly different from each other (on the basis of the overlap of their respective standard errors). Data were plotted untransformed to facilitate interpretation of the results, even when transformations were carried out.

We then calculated correlations among all pairwise combinations of across-treatment trait means and plasticities, as in Pollard et al. (2001). We tested a variety of hypotheses by the degree of matrix association between matrices representing different biological hypotheses. These tests included associations between across-treatment character means or plasticities in this experiment (foliar shade) and in the previous (photoperiod) experiments, between differences in across-treatment means and plasticities for the shade-avoidance experiment, and between either of these 
Table 1: ANOVA of haplotype, treatment, haplotype by treatment interaction, growth chamber, and shelf effects

\begin{tabular}{|c|c|c|c|c|c|c|}
\hline Trait & Haplotype (7) & Treatment (1) & $\begin{array}{l}\text { Haplotype by } \\
\text { treatment }(7)\end{array}$ & Chamber (1) & Shelf (chamber; 2) & Error (159-146) \\
\hline Leaf number & $\begin{array}{r}\mathbf{3 2 , 5 8 9 . 7 8} \\
(<.0001)\end{array}$ & $\begin{array}{r}\mathbf{8 8 , 2 2 1 . 8 0} \\
(<.0001)\end{array}$ & $\begin{array}{r}\mathbf{9 , 5 1 6 . 4 8} \\
(<.0001)\end{array}$ & $\begin{array}{r}3,440.94 \\
(.0569)\end{array}$ & $\begin{array}{r}2,747.35 \\
(.0559)\end{array}$ & 935.61 \\
\hline Rosette diameter & $\begin{array}{r}13,376.74 \\
(<.0001)\end{array}$ & $\begin{array}{r}\mathbf{8 , 3 2 9 . 2 1} \\
(.0010)\end{array}$ & $\begin{array}{l}\mathbf{6 , 1 7 8 . 0 7} \\
\quad(<.0001)\end{array}$ & $\begin{array}{r}2,737.76 \\
(.0559)\end{array}$ & $\begin{array}{r}2,138.51 \\
(.0580)\end{array}$ & 737.84 \\
\hline Bolting time & $\begin{array}{r}10,868.27 \\
(<.0001)\end{array}$ & $\begin{array}{r}\mathbf{4 3 , 9 8 1 . 0 0} \\
(<.0001)\end{array}$ & $\begin{array}{r}\mathbf{1 , 8 3 9 . 8 0} \\
(.0001)\end{array}$ & $\begin{array}{r}\mathbf{3 , 8 9 7 . 8 2} \\
(.0021)\end{array}$ & $\begin{array}{l}\mathbf{2 , 2 8 2 . 8 4} \\
\quad(0.0040)\end{array}$ & 399.56 \\
\hline Stem length $(\log )$ & $\begin{array}{l}\mathbf{1 0 . 5 9} \\
(<.0001)\end{array}$ & $\begin{array}{l}.38 \\
(.4848)\end{array}$ & $\begin{array}{l}3.87 \\
(.0001)\end{array}$ & $\begin{array}{l}.50 \\
(.4233)\end{array}$ & $\begin{array}{l}.14 \\
(.8299)\end{array}$ & .78 \\
\hline No. basal stems & $\begin{array}{l}\mathbf{6 1 . 2 0} \\
(<.0001)\end{array}$ & $\begin{array}{l}28.51 \\
(.0636)\end{array}$ & $\begin{array}{l}25.21 \\
(.0048)\end{array}$ & $\begin{array}{l}39.93 \\
(.0286)\end{array}$ & $\begin{array}{l}11.97 \\
(.2338)\end{array}$ & 8.14 \\
\hline First seed set $(\log )$ & $\begin{array}{l}.27 \\
(.0588)\end{array}$ & $\begin{array}{l}\mathbf{1 . 3 2} \\
(.0024)\end{array}$ & $\begin{array}{l}.13 \\
(.4417)\end{array}$ & $\begin{array}{l}.48 \\
(.0624)\end{array}$ & $\begin{array}{l}.10 \\
(.4576)\end{array}$ & .13 \\
\hline Main stem fruits & $\begin{array}{r}617,044.86 \\
(<.0001)\end{array}$ & $\begin{array}{l}33.58 \\
(.9854)\end{array}$ & $\begin{array}{r}189,202.15 \\
(.0739)\end{array}$ & $\begin{array}{r}48,447.29 \\
(.4861)\end{array}$ & $\begin{array}{r}45,845.09 \\
(.6313)\end{array}$ & $99,299.78$ \\
\hline Basal fruits (log) & $\begin{array}{l}2.64 \\
(.3641)\end{array}$ & $\begin{array}{l}.47 \\
(.6561)\end{array}$ & $\begin{array}{l}3.13 \\
(.4580)\end{array}$ & $\begin{array}{l}1.32 \\
(.2527)\end{array}$ & $\begin{array}{l}.57 \\
(.7873)\end{array}$ & 2.38 \\
\hline
\end{tabular}

Note: All effects are considered fixed. Mean square values are reported, with the associated $P$ values in parentheses; MS values associated with significant $P$ values after a sequential Bonferroni correction are highlighted in boldface. Transformations of raw data are indicated in parentheses after each trait's description. Degrees of freedom are indicated in parentheses below each effect.

and geographical or phylogenetic distances (calculated by both algorithms discussed above). All tests were carried out by matrix correlation analysis (Mantel test; Manly 1986; Smouse et al. 1986; Cheverud et al. 1989). For each test, a matrix correlation coefficient was calculated, and its significance was assessed by 1,000 randomization tests. The dissimilarity matrices of phenotypic characters (across-treatment means and plasticities) were based on Euclidean distances (Sneath and Sokal 1973) and were calculated using the NT-SYS (NT-SYS 1996) software package.

\section{Results}

\section{Network Phylogenies}

Analysis of sequence variation for the 2,100 base pair cpDNA region examined revealed sequence differences between $0.2 \%$ and $2.3 \%$ between pairs of haplotypes (not including the in/del data; Pollard et al. 2001). The GTR and mean distance matrices calculated from sequences of intergenic regions of the chloroplast genome were very similar (Pearson's correlation coefficient $=0.9775, P<$ .0001 ). However, the topologies of the reticulograms produced from these two distance methods differed with respect to the placement of a single haplotype (Sweden 1352; fig. 1). The ambiguity for placement of Sweden 1352 is not too surprising, given that the sum of the lengths of the branches connecting the common axial node with Denmark 1288 was zero (fig. 1, upper diagram). The general effect of adding in/dels to the distance matrix was to increase the overall length of most branches without having much impact on their lengths relative to each other. Hence, the in/del data primarily served to reinforce the pattern of genetic distances emerging from the substitution data.

The two stopping criteria for the addition of reticulations produced different numbers of additional connections to the additive UPGMA trees (fig. 1). The $\mathrm{Q}_{1}$ method, which produces more stringent conditions for extra edges to the tree, indicated that no additional connections were necessary to improve the fit of the cladogram to the data matrix. The $\mathrm{Q}_{2}$ method, however, indicated that two additional connections were warranted, and the same two connections were indicated for both trees (fig. 1).

\section{Variation of Across-Treatment Character Means and Plasticities}

We found significant differences among haplotypes for most characters except time to first seed set and basal fruit production (table 1). The treatment effect was significant for all vegetative traits as well as for time to first seed set. Significant variation among haplotypes for plasticity was found again for all vegetative characters and additionally for the length of the main stem and for number of basal stems. There were significant microenvironmental effects only for bolting time.

Leaf number and bolting time showed similar reaction norms (fig. $2 a, 2 c$ ), with plants producing fewer leaves and bolting earlier under low $\mathrm{R}$ : FR, in accordance with the 

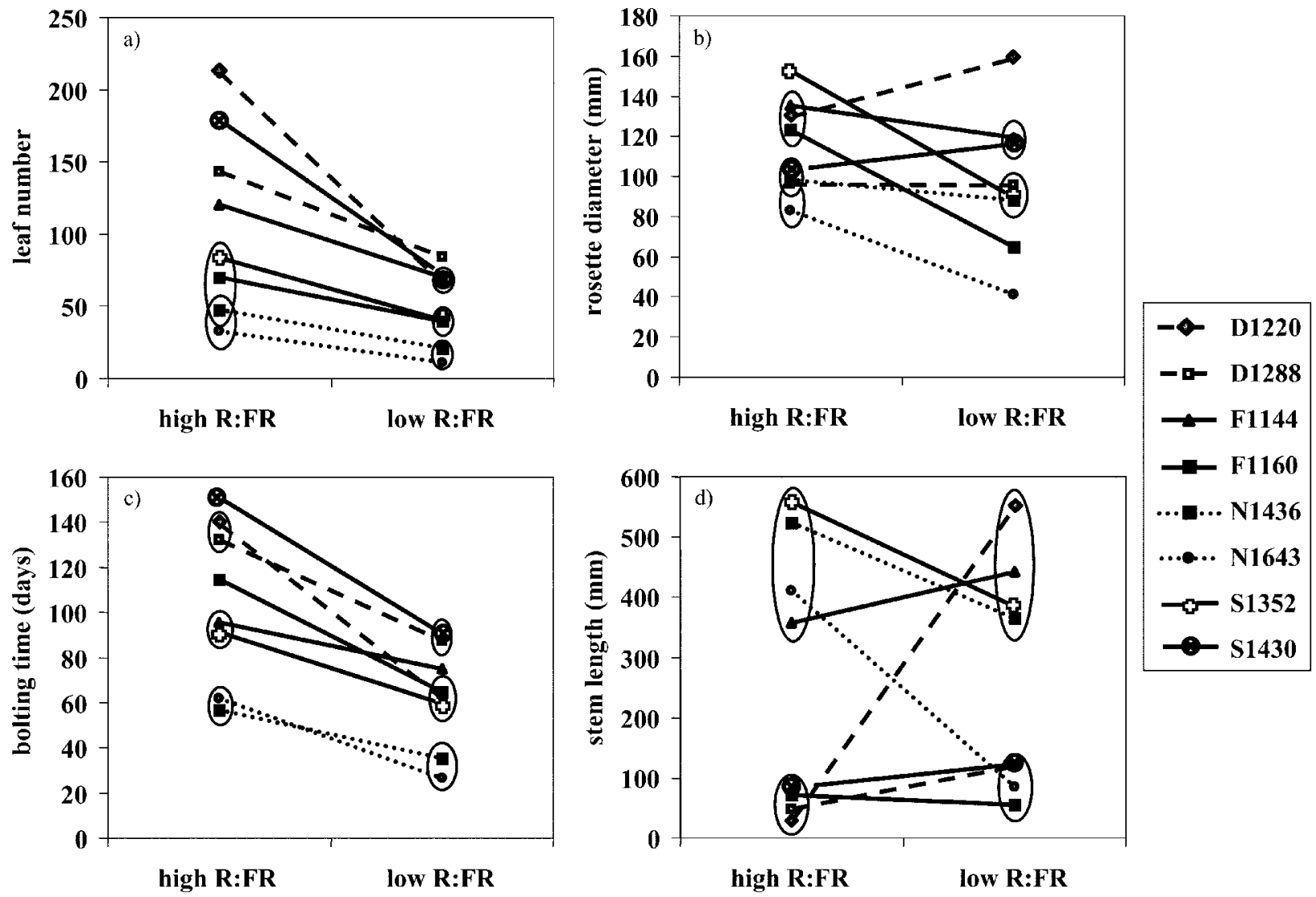

Figure 2: Reaction norms of the eight populations for vegetative traits and plant size. Ellipses indicate within-environment means that were not significantly different from each other.

shade-avoidance hypothesis. Some haplotypes (e.g., the two Norwegian accessions) produced fewer leaves and flowered much earlier than the rest, regardless of the environment. The reaction norms for rosette diameter (fig. $2 b$ ) were more heterogeneous, with no clear across-environment trend; some accessions (e.g., Norway 1643) had smaller rosettes under low R : FR than under high R : FR, but others showed the reverse pattern (e.g., Denmark 1220), while still others did not react at all to the change in light quality (e.g., Denmark 1288). Stem length was marked by even more contrasting reaction norms (fig. 2d), again with Norway 1643 plants being much shorter under low R : FR than under high R : FR (contrary to the shadeavoidance hypothesis) but with Denmark 1220 being much taller; the remaining haplotypes were clearly divided into two groups, one producing plants $<10 \mathrm{~cm}$ tall and the other yielding individuals between 40 and $60 \mathrm{~cm}$ regardless of the conditions.

The pattern for basal stem production (fig. $3 a$ ) was very similar to the one observed for plant height, with the short haplotypes producing around four basal stems and the tall ones producing around six basal stems. There was little heterogeneity among the reaction norms for time to first seed set (fig. 3b), with only the two Danish accessions showing any appearance of plasticity (in opposite directions). Main stem fruit production (fig. $3 c$ ) showed a high heterogeneity among haplotypes, which varied from $<10$ to $>700$ fruits; despite the formally nonsignificant genotype by environment interaction, Denmark 1220 went from being the lowest-ranking haplotype under high $\mathrm{R}$ : FR to being the highest one in the other treatment, while Norway 1643 showed the opposite response; this suggests some degree of specialization for open sun versus foliar shade in a subset of our haplotypes. Basal fruit production (fig. 3d) was not significantly variable either by haplotype or by environment, and while some of the reaction norms did show more apparent plasticity than others, the ellipses marking overlap were very large; nevertheless, some plants produced as little as five basal fruits and others as many as 170 . 

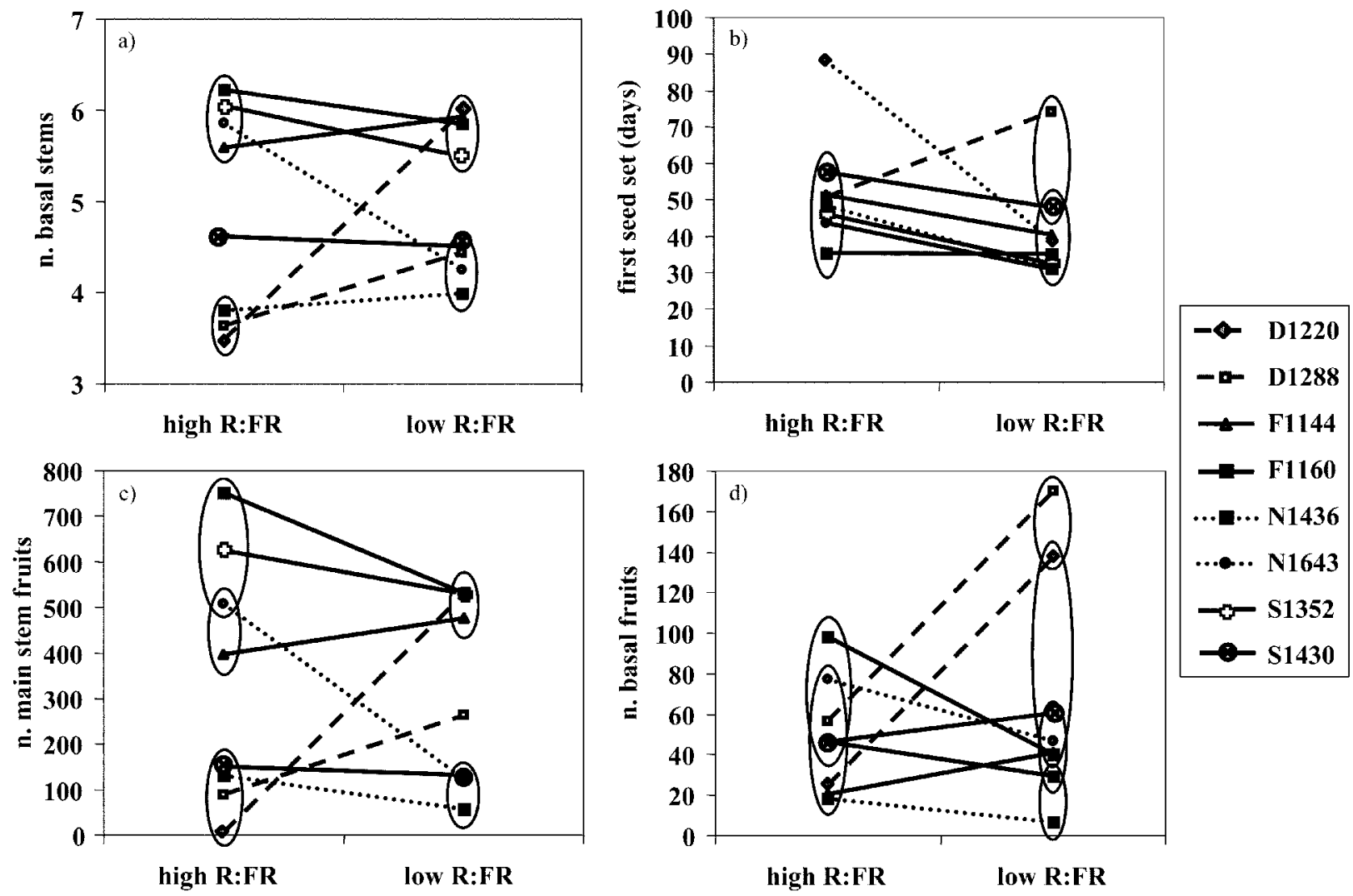

Figure 3: Reaction norms of the eight populations for reproductive traits. Ellipses indicate within-environment means that were not significantly different from each other.

\section{Coevolution of Across-Treatment Character Means and Plasticities}

We found that 12 of the 28 possible correlations between across-treatment character means turned out to be significant among accessions (table 2; notice that these significant tests are rather conservative given the small number of accessions). This was a much higher number (six out of 28) than we found significant in our article on photoperiod (Pollard et al. 2001), although five of the same correlations were significant in both data sets (indicated by italics in table 2). Interestingly, a test comparing the across-treatment means correlations in the two studies found a significant association between the two $(r=$ $0.40, P=.0380)$, indicating that about $16 \%$ of the variance in one matrix can be explained by the variance in the other one.

We found that 13 out of 28 correlations between plasticities were significant in this experiment, compared with only two in the photoperiod experiment (table 2), both of which overlapped between the sets. The matrix asso- ciation between experiments was again significant $(r=$ $0.47, P=.0060$ ), with variation in one matrix explaining $22 \%$ of the variation in the other one.

We also compared the degree of correlation between the plasticities and across-treatment means of the same traits in the shade-avoidance experiment, as already done with the photoperiod data (Pollard et al. 2001). The plasticities and across-treatment means of leaf number, basal stems, time to first seed set, and main stem fruits were significantly correlated, with one data set explaining between $7 \%$ and $44 \%$ of the variance of the other one (table 3 ).

\section{Correlates of Phenotypic Differentiation}

We investigated two additional hypotheses about the determinants of phenotypic variation in our accessions: that the phenotypic differentiation among haplotypes can be explained at least in part by their geographical separation and that the phenotypic differences can be explained par- 
tially by the degree of phylogenetic relatedness among our accessions.

The geographical differentiation hypothesis was clearly rejected for most but not all traits. Differences among accessions in across-treatment mean basal fruits and, marginally, mean stem length, plasticity of leaf number, and plasticity of basal stems were related to the geographical distance among those accessions (details not shown). However, the amount of phenotypic variance explained by geography was as low as $4 \%$ and was at most $21 \%$.

Phylogenetic relatedness was never significantly associated with phenotypic differences among haplotypes, with the exception of a marginally significant effect relating the mean phylogenetic matrix and differences in across-treatment mean leaf number (details not shown). Both measures of phylogenetic distances were instead positively related (albeit marginally) with geographical distance. It is relevant to point out that although the phylogenetic method used in our earlier study (Pollard et al. 2001) was different from the network phylogenies presented here, the correlation between the phylogenetic distances calculated in the earlier study and the distances used here was very high: $0.98(P=.0020)$ with the GTR distances and 0.95 $(P=.0020)$ with the mean distances. Not surprisingly, the GTR and mean phylogenetic distances were also highly correlated: $0.97(P=.0020)$.

\section{Discussion}

The goal of this article was to study the intraspecific evolution of different aspects of the reaction norms in response to foliar shade of several accessions of Arabidopsis thaliana and to compare the results with those from a similar study on response to day length (Pollard et al. 2001). The rationale underlying the study was based on these observations: the responses to these two aspects of light availability are likely to be integrated in this plant; however, given the widely different spatial scales of variation of day length and light spectral quality, one might expect very different patterns of evolution of the respective reaction norms. In particular, we should observe concerted evolution of across-treatment character means (but not plasticities) in response to day length (which was in fact the pattern uncovered by Pollard et al. [2001]) but concerted evolution of plasticities (but not across-treatment means) in response to light quality, which is partly what we found here.

In the light-quality experiment, we found variation among haplotypes for across-treatment trait means and/ or plasticities for almost every trait that was measured (question 1). Since these are differences among accessions that are widely separated in space, they should be seen as the outcome of past selective forces, constraints, or his- torical contingency rather than as an estimate of currently available variation for future responses to selection (Armbruster and Schwaegerle 1996; Schluter 1996; Merila and Bjorklund 1999). The latter can be assessed through separate studies of response to artificial selection or of genetic variation within each accession (Callahan and Pigliucci 2002).

The across-treatment trait means and plasticities to foliar shade generally followed mixed patterns of evolution, as indicated by the presence of some significant correlations between the means and plasticities. It is, however, very clear that neither geographic proximity (question 5) nor genetic relatedness explains the patterns of variation of most traits. A similar set of results has been detected in the same accessions when studied under contrasting day-length treatments (Pollard et al. 2001), although the specific traits showing significant correlations between across-treatment means and plasticities were different in the other study, and there we found a weaker link between plasticities and means of the same characters.

\section{Trait Coevolution and Phenotypic Integration (Questions 2, 3, and 4)}

We found evidence of some coevolution among acrosstreatment trait means (question 2) in the light-quality experiment, not unlike other comparative studies published so far (e.g., Ackerly and Donoghue 1998; Hodkinson et al. 1998; Villar et al. 1998) and to a level higher than the one detected in our accessions in our earlier study (though the specific traits involved were somewhat different; Pollard et al. 2001). In both studies, we found a strong positive correlation between rosette leaf number and days to bolting. Such a relationship has been previously described (Mitchell-Olds 1996; Pigliucci et al. 1998) and is probably largely the result of a fundamental developmental constraint in Arabidopsis: the only way to produce more rosette leaves is to postpone the switch to the reproductive phase of the life cycle, even though natural selection actually favors earlier reproduction with more leaves (Callahan and Pigliucci 2002).

The trait plasticities appeared to be about as integrated as the across-treatment trait means (question 2). This is in stark contrast to the analogous picture that emerged from our day-length study, where very few plasticities demonstrated evidence of coevolution among the same haplotypes (Pollard et al. 2001). Evidently, in response to changes in light quality (but not in day length), a higher degree of plasticity in several characters is elicited, and most important are all those normally thought of as involved in shade avoidance: leaf production, bolting time, plant architecture, and height. Such a tight coevolution of the plasticities of characters involved in shade avoidance 
Table 2: Correlations among character grand means and plasticities calculated using haplotype means

\begin{tabular}{|c|c|c|c|c|c|c|c|c|}
\hline & Leaves & Rosette & Bolting & Stem length & Basal stems & Seed set & Main fruits & Basal fruits \\
\hline \multicolumn{9}{|c|}{ Character grand means: } \\
\hline Leaves & 1.00 & $\ldots$ & $\ldots$ & $\ldots$ & $\ldots$ & $\ldots$ & $\ldots$ & $\cdots$ \\
\hline Rosette & .15 & 1.00 & $\ldots$ & $\ldots$ & $\ldots$ & $\ldots$ & $\ldots$ & $\ldots$ \\
\hline Bolting & $.89^{*}$ & -.10 & 1.00 & $\ldots$ & $\ldots$ & $\ldots$ & $\ldots$ & $\ldots$ \\
\hline Stem length & -.71 & .46 & $-.87^{\star}$ & 1.00 & $\ldots$ & $\ldots$ & $\ldots$ & $\ldots$ \\
\hline Basal stems & $.86^{\star}$ & .03 & $.76^{\star}$ & -.62 & 1.00 & $\ldots$ & $\ldots$ & $\ldots$ \\
\hline Seed set & $.88^{*}$ & .11 & $.72^{\star}$ & -.68 & $.88^{\star}$ & 1.00 & $\ldots$ & $\ldots$ \\
\hline Main fruits & $-.75^{\star}$ & .37 & $-.89^{*}$ & $.98^{*}$ & -.63 & $-.74^{*}$ & 1.00 & $\ldots$ \\
\hline Basal fruits & -.64 & -.18 & -.67 & .64 & -.34 & -.66 & $.75^{\star}$ & 1.00 \\
\hline \multicolumn{9}{|l|}{ Plasticities: } \\
\hline Leaves & 1.00 & $\ldots$ & $\ldots$ & $\ldots$ & $\ldots$ & $\ldots$ & $\ldots$ & $\ldots$ \\
\hline Rosette & $-.79^{*}$ & 1.00 & $\ldots$ & $\ldots$ & $\ldots$ & $\ldots$ & $\ldots$ & $\ldots$ \\
\hline Bolting & $.81^{\star}$ & $-.81^{\star}$ & 1.00 & $\ldots$ & $\ldots$ & $\ldots$ & $\ldots$ & $\ldots$ \\
\hline Stem length & $-.83^{*}$ & $.84^{*}$ & -.70 & 1.00 & $\ldots$ & $\ldots$ & $\ldots$ & $\ldots$ \\
\hline Basal stems & $.77^{\star}$ & -.42 & .70 & -.59 & 1.00 & $\ldots$ & $\ldots$ & $\ldots$ \\
\hline Seed set & .62 & -.43 & .61 & -.60 & $.89^{*}$ & 1.00 & $\ldots$ & $\ldots$ \\
\hline Main fruits & $-.79^{*}$ & $.78^{\star}$ & -.67 & $.97^{\star}$ & -.50 & -.50 & 1.00 & $\ldots$ \\
\hline Basal fruits & -.64 & $.78^{\star}$ & -.68 & $.81^{\star}$ & -.24 & -.28 & $.89^{*}$ & 1.00 \\
\hline
\end{tabular}

is expected if this phenotypic syndrome is indeed adaptive (Givnish 1982; Dudley and Schmitt 1996; Ballaré 1999; Dorn et al. 2000; Weinig 2000; Donohue et al. 2001). This plasticity syndrome seems to be associated with a high degree of integration also in the across-treatment character means, several of which were not independent of the plasticities under our environments.

Of the correlations between the plasticities of reproductive traits, two linked stem length and fruit production. The first correlation was between stem height and fruit production of the same stem, which is easily explained by a simple architectural constraint: these plants tend to produce fruits at regular intervals on the main stem, so a correlation between the plasticities of these two characters is not surprising. The additional relationship between the plasticity of main stem size and basal stem fruit number implies that conditions that affect stem elongation also tend to modulate basal fruit production in the same fashion. This is in accordance with the findings of Hempel and Feldman (1994) that the basal inflorescences are initiated in Arabidopsis only after a given number of flowers (on the main stem) have matured and opened. However, it is also known that main stem length and branching patterns do not have to be related, since gibberellininsensitive and deficient mutants can uncouple these two traits (Ross et al. 1997) and potentially their plasticities (because gibberellin is responsive to light conditions; Chory and Li 1997).

Overall, it is interesting to note that when we expected across-treatment character means and not plasticities to be subjected to natural selection for adaptation to coarsegrained environmental conditions (variation in day length; Pollard et al. 2001), that is what we found. On the contrary, when we expected plasticities rather than across-treatment trait means to be under selection in fine-grained environments (foliar shade), we found both sets of characters to be highly integrated (although the correlations among trait means may have been somewhat inflated by the unnaturally high photoperiod experienced by all plants in the second experiment; question 3).

Schlichting inspected the degree of integration of plastic responses within three species of Phlox and two species of

Table 3: Matrix correlation relating differences between populations in their means and plasticities in response to foliar shade for the same trait

\begin{tabular}{lcc}
\hline Character & Correlation & $P$ value $(1,000)$ \\
\hline Leaf number & +.66 & .0030 \\
Rosette diameter & +.05 & .4216 \\
Bolting time & +.19 & .1738 \\
Stem length & -.19 & .1189 \\
Basal stems & +.41 & .0270 \\
First seed set & +.40 & .0260 \\
Main stem fruits & $-.27^{\mathrm{a}}$ & .0569 \\
Basal fruits & +.29 & .1129 \\
\hline
\end{tabular}

Note: Measured as Euclidean distances. Significance tested with 1,000 randomizations. Boldface indicates significance.

a Indicates marginal significance. 
Sesbania (Schlichting 1986, 1989). He found that plasticity correlations are different both within species and among species within the same genus, indicating lability of phenotypic correlations; however, he was unable to pinpoint a plausible ecological or evolutionary rationale for such variation. Newman (1994) found significant plasticity correlations for different traits within families of spadefoot toads (Scaphiopus couchii). He concluded that these correlations might cause trade-offs such that the toads are unable to exhibit the full array of optimal reaction norms. Our study is one of the few available suggesting that the degree of phenotypic integration of both across-treatment means and plasticities may indeed be adaptive, as originally postulated by Berg (1960) only for trait means (but see Armbruster et al. 1999 for less clear-cut results), and may be related to the grain of environmental heterogeneity experienced by the organism.

Another question related to the evolution of acrosstreatment character means and plasticities that has often been raised is whether the mean and plasticity of the same trait can evolve separately (question 4), as originally suggested by Bradshaw (1965) and implied by Schmalhausen (1949). Evidence that this is possible comes from Schlichting and Levin (1986) and Zimmerman (1976) and is discussed in Schlichting (1986) and to some extent in Via et al. (1995; more references and discussion in Schlichting and Pigliucci 1998). The answer emerging from our data (as well as from our study of response to day length in the same taxa; Pollard et al. 2001) seems to be what Bradshaw predicted: it depends. Four of our mean-plasticity correlations were significant out of a total of eight. It seems reasonable to conclude that plasticities and their acrosstreatment trait means behave exactly as any other group of characters one might encounter: sometimes they are related, either because of shared genetic machinery or because of their functional ecology, but the association is by no means automatically implied by the fact that these are two properties of the same reaction norm (Pigliucci 2001).

\section{Evolution in Fine versus Coarse-Grained Environments (Question 6)}

The picture emerging from this and our previous study (Pollard et al. 2001) is one of different evolutionary trajectories of the same traits in response to distinct environmental conditions. While we did find a significant association between the patterns of correlations of both across-treatment trait means and plasticities in the two experiments, the variance observed in one experiment explained a small amount of the variance detected in the other one. Furthermore, the large difference in the degree of phenotypic integration of the plasticities of the same traits between the two experiments is in agreement with our expectations of the evolution of adaptive plasticities in response to foliar shade but not day length.

It is important that the results of these analyses be interpreted in the context of the phylogenetic information used. Since the chloroplast genome is typically maternally inherited (Sears 1980), genetic distances based on cpDNA sequence data provide an estimation of distances among maternal lineages but will accurately reflect differences among nuclear genomes only to the extent that outcrossing (lineage reticulation) is limited. This is a particularly important point for the following reasons: first, this is an intraspecific analysis, so the taxonomic units in this case presumably are intercompatible with each other; and second, virtually all of the loci controlling the characters studied are probably located in the nucleus rather than the cytoplasmic genomes. The frequency of outcrossing in this species reportedly is very low (i.e., $<2 \%$; Abbott and Gomes 1989; Loridon et al. 1997), so we might expect that reticulation events would be rare enough to maintain associations between individual chloroplast and nuclear lineages over a relatively long period of time. However, it is clear from the above analyses that the phenotypic characters studied are considerably labile with respect to cpDNA sequence differences, so it is likely that reticulation is frequent enough to allow for local adaptation of genotypes after a site or local region has been colonized.

The depiction of the relationships among the accessions examined in this analysis as a reticulogram requires some comment as well. The necessity of adding reticulations to the additive tree to obtain an adequate fit with the distance matrix is perhaps surprising since chloroplasts are haploid and their genomes are not known to recombine (Palmer et al. 1988; Clegg et al. 1991). Furthermore, this result does not seem to be an artifact of the procedures used by the TREX program, since similar nonadditive groupings were evident in trees produced by Pyramid (Lapointe 2000) and splitsgraphs (Bandelt and Dress 1992). However, the apparent reticulations could occur as a consequence of convergent changes in the chloroplast genomes of the separate lineages examined. While lateral transmission of genomic material among organelles could produce such convergent changes, this mechanism is exceedingly unlikely for convergence of chloroplast lineages because observed instances of horizontal transfer among organelles appear to be rare (Palmer et al. 2000) and because transfers among cpDNA lineages that produce convergent changes could only occur in heteroplasmic individuals, which are uncommon (e.g., Cruzan et al. 1993). A more likely mechanism is biased base substitution at specific sites that are dependent on the composition of bases at neighboring positions (Morton et al. 1997). Given that the number of base differences among the lineages examined in this study is relatively small, even a few convergent mutations could 
have a relatively pronounced effect on patterns of genetic distances and probably could account for the apparent nonadditive groupings.

The scenario suggested by our results, which may be tested by further studies on this system, is that selection has favored the evolution of across-treatment trait means in response to photoperiod and of plasticities in response to foliar shade by a process of local adaptation after colonization. This tentative conclusion can be reached by a variety of lines of evidence. First, we did not detect any association between genetic distance and phenotypic differentiation. This diminishes the likelihood that historical patterns of dispersal are a major determinant of what we are observing. Second, several characters were highly correlated with each other. While this can happen because of both constraints and selection, the two possibilities are not mutually exclusive, since selection may have created whatever genetic correlations underlie the observed pattern.

If selection did occur, this may have happened in two different fashions. On the one hand, the populations from which our accessions were sampled may have undergone lineage sorting: starting from one or more ancestral stocks, whatever selfing lines were better adapted to the local day length/foliar shade conditions would have survived and become established. On the other hand, the same populations may have undergone significant local evolution after having arrived in place. The first possibility is supported by what we know of the mode of dispersal of this species: there appear to be only weak associations between geography and genetic relatedness in Arabidopsis (Innan et al. 1997; Loridon et al. 1997; Breyne et al. 1999; Erschadi et al. 2000), which has led to the suggestion that most of the biogeography of this species can be explained by rapid postglacial long-distance dispersal, probably driven by human movements. However, the lack of phylogenetic signal in our data suggests that evolution by reticulation among lineages on a local geographic scale is more likely than lineage sorting, which would have maintained stronger associations between genetic distance and phenotypic characters.

Another possibility that may help account for local evolution over a short period of time in this highly inbred species is the appearance of novel genetic variation for quantitative traits, which can be caused solely by mutation accumulation over a period of only 10 generations (Schultz et al. 1999). Hence, the combination of mechanisms of mutation accumulation within lineages and reticulation among lineages could generate novel phenotypes and account for rapid evolution within local geographic regions.

As we mentioned at the onset, little can be said on the ecological side of this question, since not much is known of the autoecology of this species. However, what we do know indicates that Arabidopsis is rather ruderal and, hence, potentially routinely exposed to environments that could be heterogeneous for nutrients as well as light resources. Coupled with our observation that the haplotypes studied here behave as ecological generalists, with plastic vegetative traits and homeostatic fitness-related traits, this may again point toward differentiation of populations in response to locally heterogeneous environments as a major driving force of phenotypic evolution in this species. Additional comparative studies of $A$. thaliana phenotypes from contrasting habitats will continue to provide insights into the mechanisms of adaptive evolution in this highly selfing species.

\section{Acknowledgments}

We wish to thank C. Murren, C. Schlichting, and R. Small for critical readings of the manuscript. This research was supported in part by National Science Foundation grant IBN-9707552 to M.P.

\section{Literature Cited}

Abbott, R. J., and M. F. Gomes. 1989. Population genetic structure and outcrossing rate of Arabidopsis thaliana (L.) Heynh. Heredity 62:411-418.

Ackerly, D. D., and M. J. Donoghue. 1998. Leaf size, sapling allometry, and Corner's rules: phylogeny and correlated evolution in maples (Acer). American Naturalist 152:767-791.

Armbruster, W. S., and K. E. Schwaegerle. 1996. Causes of covariation of phenotypic traits among populations. Journal of Evolutionary Biology 9:261-277.

Armbruster, W. S., V. S. D. Stilio, J. D. Tuxill, T. C. Flores, and J. L. V. Runk. 1999. Covariance and decoupling of floral and vegetative traits in nine Neotropical plants: a re-evaluation of Berg's correlation-pleiades concept. American Journal of Botany 86:39-55.

Aukerman, M. J., M. Hirschfeld, L. Wester, M. Weaver, T. Clack, R. M. Amasino, and R. A. Sharrock. 1997. A deletion in the PHYD gene of the Arabidopsis Wassilewskija ecotype defines a role for phytochrome D in red/far-red light sensing. Plant Cell 9:1317-1326.

Ballaré, C. L. 1999. Keeping up with the neighbours: phytochrome sensing and other signalling mechanisms. Trends in Plant Science 4:97-102.

Bandelt, H.-J., and A. W. M. Dress. 1992. Split decomposition: a new and useful approach to phylogenetic analysis of distance data. Molecular Phylogenetics and Evolution 1:242-252.

Bell, G. 1997. Selection: the mechanism of evolution. Chapman \& Hall, New York.

Berg, R. L. 1960. The ecological significance of correlation pleiades. Evolution 14:171-180.

Bradshaw, A. D. 1965. Evolutionary significance of phe- 
notypic plasticity in plants. Advances in Genetics 13: 115-155.

Bradshaw, A. D., and K. Hardwick. 1989. Evolution and stress: genotypic and phenotypic components. Biological Journal of the Linnean Society 37:137-155.

Breyne, P., D. Rombaut, A. Van-Gysel, N. Van-Montagu, and T. Gerats. 1999. AFLP analysis of genetic diversity within and between Arabidopsis thaliana ecotypes. Molecular and General Genetics 261:627-634.

Callahan, H., and M. Pigliucci. 2002. Shade-induced plasticity and its ecological significance in wild populations of Arabidopsis thaliana. Ecology 83:1965-1980.

Cheverud, J. M., G. P. Wagner, and M. M. Dow. 1989. Methods for the comparative analysis of variation patterns. Systematic Zoology 38:201-213.

Chory, J., and J. Li. 1997. Gibberellins, brassinosteroids and light-regulated development. Plant Cell and Environment 20:801-806.

Clauss, M. J., and L. W. Aarssen. 1994. Phenotypic plasticity of size-fecundity relationships in Arabidopsis thaliana. Journal of Ecology 82:447-455.

Clegg, M. T., G. Learn, and E. Golenberg. 1991. Molecular evolution of chloroplast DNA. Pages 135-149 in T. Whittam, ed. Evolution at the molecular level. Sinauer, Sunderland, Mass.

Cruzan, M. B., M. L. Arnold, S. E. Carney, and K. R. Wollenberg. 1993. cpDNA inheritance in interspecific crosses and evolutionary inference in Louisiana irises. American Journal of Botany 80:344-350.

Densmore, R. V. 1997. Effect of day length on germination of seeds in Alaska. American Journal of Botany 84: 274-278.

Devlin, P. F., S. R. Patel, and G. C. Whitelam. 1998. Phytochrome $\mathrm{E}$ influences internode elongation and flowering time in Arabidopsis. Plant Cell 10:1479-1487.

Devlin, P. F., P. R. H. Robson, S. R. Patel, L. Goosey, R. A. Sharrock, and G. C. Whitelam. 1999. Phytochrome $\mathrm{D}$ acts in the shade-avoidance syndrome in Arabidopsis by controlling elongation growth and flowering time. Plant Physiology 119:909-915.

DeWitt, T. J., A. Sih, and D. S. Wilson. 1998. Costs and limits of phenotypic plasticity. Trends in Ecology \& Evolution 13:77-81.

Donohue, K., D. Messiqua, E. H. Pyle, M. S. Heschel, and J. Schmitt. 2001. Evidence of adaptive divergence in plasticity: density- and site-dependent selection on shade-avoidance responses in Impatiens capensis. Evolution 55:1956-1968.

Dorn, L. A., E. H. Pyle, and J. Schmitt. 2000. Plasticity to light cues and resources in Arabidopsis thaliana: testing for adaptive value and costs. Evolution 54:1982-1994.

Dudley, S. A., and J. Schmitt. 1996. Testing the adaptive plasticity hypothesis: density-dependent selection on manipulated stem length in Impatiens capensis. American Naturalist 147:445-465.

Erschadi, S., G. Haberer, M. Schoniger, and R. A. TorresRuiz. 2000. Estimating genetic diversity of Arabidopsis thaliana ecotypes with amplified fragment length polymorphism (AFLP). Theoretical and Applied Genetics 100:633-640.

Felsenstein, J. 1984. Distance methods for inferring phylogenies: a justification. Evolution 38:16-24.

Frankland, B. 1986. Perception of light quantity. Pages 219-235 in G. H. M. Kronenberg, ed. Photomorphogenesis in plants. Martinus Nijhoff/Junk, Dordrecht.

Gabriel, W., and M. Lynch. 1992. The selective advantage of reaction norms for environmental tolerance. Journal of Evolutionary Biology 5:41-59.

Gilbert, R., P. G. Jarvis, and H. Smith. 2001. Proximity signal and shade avoidance differences between early and late successional trees. Nature 411:792-795.

Gillespie, J. 1974. Polymorphism in patchy environments. American Naturalist 108:145-151.

Givnish, T. J. 1982. On the adaptive significance of leaf height in forest herbs. American Naturalist 120: 353-381.

Guo, H. W., W. Y. Yang, T. C. Mockler, and C. T. Lin. 1998. Regulations of flowering time by Arabidopsis photoreceptors. Science (Washington, D.C.) 279:1360-1363.

Hau, M., M. Wikelski, and J. C. Wingfield. 1998. A Neotropical forest bird can measure the slight changes in tropical photoperiod. Proceedings of the Royal Society of London B, Biological Sciences 265:89-95.

Hempel, F. D., and L. J. Feldman. 1994. Bi-directional inflorescence development in Arabidopsis thaliana: acropetal initiation of flowers and basipetal initiation of paraclades. Planta 192:276-286.

Hillis, D. M., C. Moritz, and B. K. Mable. 1996. Molecular systematics. Sinauer, Sunderland, Mass.

Hodkinson, D. J., A. P. Askew, K. Thompson, J. G. Hodgson, J. P. Bakker, and R. M. Bekker. 1998. Ecological correlates of seed size in the British flora. Functional Ecology 12:762-766.

Innan, H., R. Terauchi, and N. T. Miyashita. 1997. Microsatellite polymorphism in natural populations of the wild plant Arabidopsis thaliana. Genetics 146: 1441-1452.

Janoudi, A.-K., W. R. Gordon, D. Wagner, P. Quail, and K. L. Poff. 1997. Multiple phytochromes are involved in red-light-induced enhancement of first-positive phototropism in Arabidopsis thaliana. Plant Physiology 113: 975-979.

Jukes, T. H., and C. R. Cantor. 1969. Evolution of protein molecules. Pages 21-132 in N. H. Munro, ed. Mammalian protein metabolism. Academic Press, New York. Junttila, O., O. M. Heide, B. Lindgard, and A. Ernstsen. 
1997. Gibberellins and the photoperiodic control of leaf growth in Poa pratensis. Physiologia Plantarum 101: 599-605.

Kendrick, R. E., L. H. J. Kerckhoffs, A. S. Pundsnes, A. Van-Tuinen, M. Koornneef, A. Nagatani, M. J. Terry, et al. 1994. Photomorphogenic mutants of tomato. Euphytica 79:227-234.

Kimura, M. 1980. A simple method for estimating evolutionary rate of base substitutions through comparative studies of nucleotide sequences. Journal of Molecular Evolution 16:111-120.

Kuittinen, H., M. J. Sillanpaa, and O. Savolainen. 1997. Genetic basis of adaptation: flowering time in Arabidopsis thaliana. Theoretical and Applied Genetics 95: 573-583.

Kumar, S., K. Tamura, and M. Nei. 1993. Mega: molecular evolutionary genetic analysis. Version 1.0. Pennsylvania State University, University Park.

Lapointe, F.-J. 2000. How to account for reticulation events in phylogenetic analysis: a comparison of distance based methods. Journal of Classification 17:175-184.

Leimar, O. 1996. Life history plasticity: influence of photoperiod on growth and development in the common blue butterfly. Oikos 76:228-234.

Levins, R. 1963. Theory of fitness in a heterogeneous environment. II. Developmental flexibility and niche selection. American Naturalist 47:75-90.

Loridon, K., B. Cournover, C. Goubely, A. Depeiges, and G. Picard. 1997. Length polymorphism and allele structure of trinucleotide microsatellites in natural accessions of Arabidopsis thaliana. Theoretical and Applied Genetics 97:591-604.

Makarenkov, V. 2001. T-REX: reconstructing and visualizing phylogenetic trees and reticulation networks. Bioinformatics 17:664-668.

Makarenkov, V., and P. Legendre. 2000. Improving the additive tree representation of a dissimilarity matrix using reticulations. Pages 35-40 in M. Schader, ed. Data analysis classification and related methods. Springer, Berlin.

Manly, F. J. 1986. Randomization and regression methods for testing for associations with geographical, environmental and biological distances between populations. Researches on Population Ecology (Kyoto) 28:201-218.

Merila, J., and M. Bjorklund. 1999. Population divergence and morphometric integration in the greenfinch (Carduelis chloris): evolution against the trajectory of least resistance? Journal of Evolutionary Biology 12:103-112.

Mitchell-Olds, T. 1996. Genetic constraints on life-history evolution: quantitative-trait loci influencing growth and flowering in Arabidopsis thaliana. Evolution 50:140-145.

Morton, B. R., V. M. Oberholzer and M. T. Clegg. 1997. The influence of specific neighboring bases on substi- tution bias in noncoding regions of the plant chloroplast genome. Journal of Molecular Evolution 45:227-231.

Mozley, D., and B. Thomas. 1995. Developmental and photobiological factors affecting photoperiodic induction in Arabidopsis thaliana Heynh. Landsberg erecta. Journal of Experimental Botany 46:173-179.

Newman, R. A. 1994. Genetic variation for phenotypic plasticity in the larval life history of spadefoot toads (Scaphiopus couchii). Evolution 48:1773-1785.

NT-SYS. 1996. NT-SYS pc. Exeter Software, Setauket, N.Y. Palmer, J., R. Jansen, H. Michaels, M. Chase, and J. Manhart. 1988. Chloroplast DNA variation and plant phylogeny. Annals of the Missouri Botanical Garden 75: 1180-1206.

Palmer, J. D., K. L. Adams, Y. R. Cho, C. L. Parkinson, Y. L. Qiu, and K. M. Song. 2000. Dynamic evolution of plant mitochondrial genomes: mobile genes and introns and highly variable mutation rates. Proceedings of the National Academy of Sciences of the USA 97: 6960-6966.

Pigliucci, M. 1998. Ecological and evolutionary genetics of Arabidopsis. Trends in Plant Science 3:485-489.

- 2001. Phenotypic plasticity: beyond nature and nurture. Johns Hopkins University Press, Baltimore.

Pigliucci, M., and C. D. Schlichting. 1998. Reaction norms of Arabidopsis. V. Flowering time controls phenotypic architecture in response to nutrient stress. Journal of Evolutionary Biology 11:285-301.

Pigliucci, M., G. A. Tyler III, and C. D. Schlichting. 1998. Mutational effects on constraints on character evolution and phenotypic plasticity in Arabidopsis thaliana. Journal of Genetics 77:95-103.

Pollard, H., M. Cruzan, and M. Pigliucci. 2001. Comparative studies of reaction norms in Arabidopsis. I. Evolution of response to daylength. Evolutionary Ecology Research 3:129-155.

Pyke, K. 1994. Arabidopsis: its use in the genetic and molecular analysis of plant morphogenesis. New Phytologist 128:19-37.

Ross, J. J., I. C. Murfet, and J. B. Reid. 1997. Gibberellin mutants. Physiologia Plantarum 100:550-560.

Schlichting, C. D. 1986. The evolution of phenotypic plasticity in plants. Annual Review of Ecology and Systematics 17:667-693.

1989. Phenotypic integration and environmental change. BioScience 39:460-464.

Schlichting, C. D., and D. A. Levin. 1986. Phenotypic plasticity: an evolving plant character. Biological Journal of the Linnean Society 29:37-47.

Schlichting, C. D., and M. Pigliucci. 1998. Phenotypic evolution: a reaction norm perspective. Sinauer, Sunderland, Mass. 
Schluter, D. 1996. Adaptive radiation along genetic lines of least resistance. Evolution 50:1766-1774.

Schmalhausen, I. I. 1949. Factors of evolution: the theory of stabilizing selection. University of Chicago Press, Chicago.

Schmitt, J. 1997. Is photomorphogenic shade avoidance adaptive? perspectives from population biology. Plant Cell and Environment 20:826-830.

Schmitt, J., and R. D. Wulff. 1993. Light spectral quality, phytochrome and plant competition. Trends in Ecology \& Evolution 8:47-50.

Schonwiese, C.-D., and J. Rapp. 1997. Climate trend atlas of Europe based on observations, 1891-1990. Kluwer, Dordrecht.

Schultz, S. T., M. Lynch, and J. H. Willis. 1999. Spontaneous deleterious mutation in Arabidopsis thaliana. Proceedings of the National Academy of Sciences of the USA 96:11393-11398.

Sears, B. B. 1980. Elimination of plastids during spermatogenesis and fertilization in the plant kingdom. Plasmid 4:233-255.

Sharbel, T. F., B. Haubold, and T. Mitchell-Olds. 2000. Genetic isolation by distance in Arabidopsis thaliana: biogeography and postglacial colonization of Europe. Molecular Ecology 9:2109-2118.

Smith, H., and G. C. Whitelam. 1997. The shade avoidance syndrome: multiple responses mediated by multiple phytochromes. Plant Cell and Environment 20:840-844.

Smouse, P. E., J. C. Long, and R. R. Sokal. 1986. Multiple regression and correlation extensions of the Mantel test of matrix correspondence. Systematic Zoology 35: 627-632.

Sneath, P. H. A., and R. R. Sokal. 1973. Numerical taxonomy. W. H. Freeman, San Francisco.

Sokal, R. R., and F. J. Rohlf. 1995. Biometry. W. H. Freeman, New York.

Somers, D. E., P. F. Devlin, and S. A. Kay. 1998. Phytochromes and cryptochromes in the entrainment of the Arabidopsis circadian clock. Science (Washington, D.C.) 282:1488-1490.

Swofford, D. L., G. J. Olsen, P. J. Waddell, and D. M. Hillis. 1996. Phylogenetic inference. Pages 407-514 in
B. K. Mable, ed. Molecular systematics. Sinauer, Sunderland, Mass.

Taberlet, P., L. Gielly, G. Pautou, and J. Bouvet. 1991. Universal primers for amplification of three non-coding regions of chloroplast DNA. Plant Molecular Biology 17:1105-1109.

Thompson, L. 1994. The spatiotemporal effects of nitrogen and litter on the population dynamics of Arabidopsis thaliana. Journal of Ecology 82:63-68.

Vander-Zwan, C., S. A. Brodie, and J. J. Campanella. 2000. The intraspecific phylogenetics of Arabidopsis thaliana in worldwide populations. Systematic Botany 25:47-59. van Tienderen, P. H. 1991. Evolution of generalists and specialists in spatially heterogeneous environments. Evolution 45:1317-1331.

- 1997. Generalists, specialists, and the evolution of phenotypic plasticity in sympatric populations of distinct species. Evolution 51:1372-1380.

Via, S., R. Gomulkiewicz, G. De Jong, S. M. Scheiner, C. D. Schlichting, and P. H. van Tienderen. 1995. Adaptive phenotypic plasticity: consensus and controversy. Trends in Ecology \& Evolution 10:212-216.

Villar, R., E. J. Veneklaas, P. Jordano, and H. Lambers. 1998. Relative growth rate and biomass allocation in 20 Aegilops (Poaceae). New Phytologist 140:425-437.

Weinig, C. 2000. Differing selection in alternative competitive environments: shade-avoidance responses and germination timing. Evolution 54:124-136.

Whitelam, G. C., and P. F. Devlin. 1998. Light signalling in Arabidopsis. Plant Physiology and Biochemistry 36: 125-133.

Winn, A. A. 1996. Adaptation to fine-grained environmental variation: an analysis of within-individual leaf variation in an annual plant. Evolution 50:1111-1118.

Zhang, J., and M. J. Lechowicz. 1994. Correlation between time of flowering and phenotypic plasticity in Arabidopsis thaliana (Brassicaceae). American Journal of Botany $81: 1336-1342$.

Zimmerman, C. A. 1976. Growth characteristics of weediness in Portulaca oleracea L. Ecology 57:964-974.

Associate Editor: Isabelle Olivieri 
Copyright $\odot 2003$ EBSCO Publishing 